\title{
Synthesis of 1-(4-bromo-2-fluorophenyl)-1,3-dihydro-2H-imidazo[4,5-c] pyridin-2-one
}

Linxiao Wang, Wei Lu, Zhen Xiao, Min Zhou, Jiqing Li, Shan Xu

School of Pharmacy, Jiangxi Science \& Technology Normal University, Nanchang 330013, China

Corresponding author: Shan Xu

ABSTRACT: 1-(4-Bromo-2-fluorophenyl)-1,3-dihydro-2H-imidazo[4,5-c]pyridin-2-one (1) is an important intermediate for the synthesis of many biologically active compounds. It was synthesized from pyridin-4-ol (7) and 4-bromo-2-fluoroaniline through five steps including nitration, chlorination, $N$-alkylation, reduction and condensation. The structures of the compound 8 was confirmed by ${ }^{1} \mathrm{H}$ NMR spectrums and target compound 1 confirmed by Mass spectra.

KEYWORD: 1-(4-Bromo-2-fluorophenyl)-1,3-dihydro-2H-imidazo[4,5-c]pyridin-2-one; Pyridin-4-ol; Synthesis

\section{INTRODUCTION}

Cancer is a disease caused by normal cells changing so that they grow in an uncontrolled way. Although many anti-tumor drugs and surgeries are available, the slow efficacy of the anti-tumor drugs and the cancer recurrence are still problems ${ }^{[1-2]}$. In recent years, there were many small molecule anticancer drugs had been reported. Among them, 1-(4-bromo2-fluorophenyl)-1,3-dihydro- $2 \mathrm{H}$-imidazo[4,5-

c]pyridin-2-one (1) is an significant intermediate for the synthesis of many biologically active compounds. Therefore, design and synthesis of 1-(4-bromo-2fluorophenyl)-1,3-dihydro- $2 \mathrm{H}$-imidazo[4,5-

c]pyridin-2-one (1) derivative as small molecule inhibitors played a essential role in the study of anticancer.

Many 1-(4-bromo-2-fluorophenyl)-1,3-dihydro$2 \mathrm{H}$-imidazo[4,5-c]pyridin-2-one (1) derivatives which exhibited potential biological activities, such as 1-methyl-3-phenyl-1,3-dihydro-2H-imidazo[4,5c]pyridin-2-one(2) ${ }^{[3]}, 1,8$-dimethyl-1,3-dihydro- $2 \mathrm{H}$ imidazo[4,5-b]quinolin-2-one(3) ${ }^{[4]}, \quad 8$-bromo-1-(2chlorophenyl)-3-methyl-1,3-dihydro-2H-

imidazo[4,5-c]quinolin-2-one (4) ${ }^{[5]}$, 4-(mesityloxy)3,6-dimethyl-1-(pentan-3-yl)-1,3-dihydro-2Himidazo[4,5-c]pyridin-2-one(5) ${ }^{[6]}, \quad$ 1-(4-(2isocyanopropan-2-yl)phenyl)-3-methyl-8-(quinolin3-yl)-1,3-dihydro-2H-imidazo[4,5-c]quinolin-2-one $\left(6{ }^{[7]}\right.$, these 1-(4-bromo-2-fluorophenyl)-1,3dihydro- $2 \mathrm{H}$-imidazo[4,5-c]pyridin-2-one (1) derivatives showed biological activity.
Most of the synthetic methods of 1-(4-bromo-2fluorophenyl)-1,3-dihydro-2H-imidazo[4,5c]pyridin-2-one (1) which reported in the literature have the drawbacks, such as complicated reaction conditions ${ }^{[8]}$. Pyridin-4-ol (7) is a key intermediate for synthesizing 1-(4-bromo-2-fluorophenyl)-1,3dihydro- $2 H$-imidazo[4,5-c]pyridin-2-one (1). The synthesis of the target compound is necessary. The structures of representative compounds were shown in Fig. 1 and Fig 2.
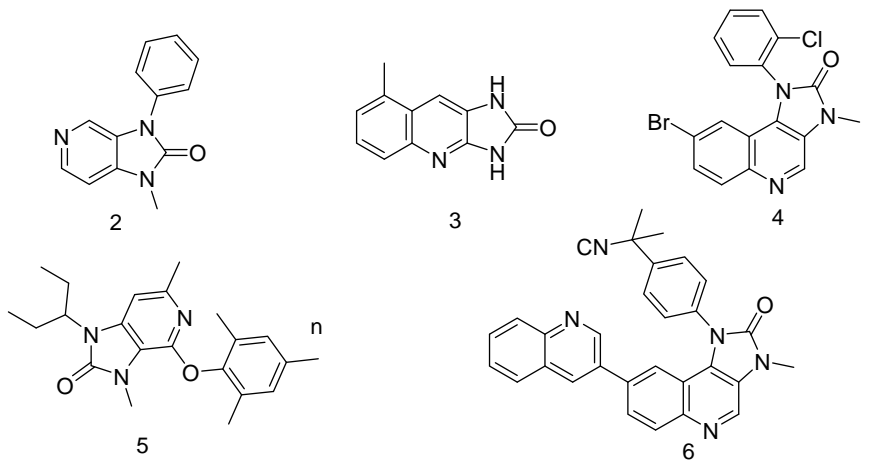

Fig.1 Structures of some drugs or active compounds containing 1,3-dihydro- $2 \mathrm{H}$-imidazo[4,5-c]pyridin-2-one<smiles>O=c1[nH]c2cnccc2n1-c1ccc(Br)cc1F</smiles>

Fig.2 Structure of the target compound 1 


\section{MATERIALS AND METHODS}

NMR spectrum were performed using Bruker 500 $\mathrm{MHz}$ spectrometers (Bruker Bioscience, Billerica,MA, USA) with TMS as an internal standard.Mass spectra (MS) were taken in ESI mode on Agilent 1100 LC-MS (Agilent, Palo Alto, CA, USA).All the materials were obtained from commercial suppliers and used without purification, unless otherwise specified. Yields were not optimized. TLC analysis was carried out on silica gel plates GF254 (Qindao Haiyang Chemical).

\section{SYNTHESIS OF COMPOUNDS}

The structures and the synthetic route were shown in Scheme 1.

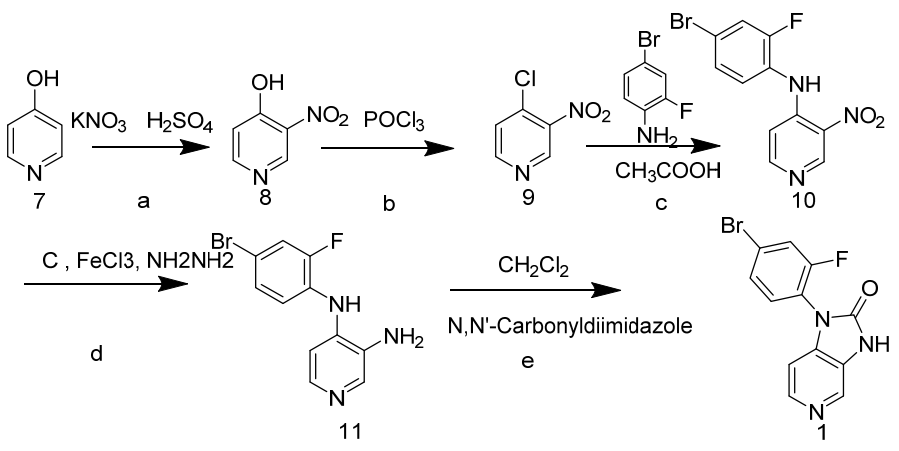

Scheme 1 . The synthetic route of Compound 1

Reagents and conditions:(a) $\mathrm{KNO}_{3}, \mathrm{H}_{2} \mathrm{SO}_{4}, 110^{\circ} \mathrm{C}$, $10 \mathrm{~h}$ (b) $\mathrm{POCl}_{3}, 110{ }^{\circ} \mathrm{C}, 3 \mathrm{~h}$ (c) 4-Bromo-2fluoroaniline, $25{ }^{\circ} \mathrm{C}, 10 \mathrm{~h}(\mathrm{~d}) \mathrm{C}, \mathrm{FeCl}_{3}, \mathrm{NH}_{2} \mathrm{NH}_{2}, 1 \mathrm{~h}$; (e) N,N'-Carbonyldiimidazole, $\mathrm{CH}_{2} \mathrm{Cl}_{2}$,

\section{3-NITROPYRIDIN-4-OL (8)}

Pyridin-4-ol (10 g, $0.105 \mathrm{~mol})$ is dissolved in conc. $\mathrm{H}_{2} \mathrm{SO}_{4}(60 \mathrm{~mL})$ at $0{ }^{\circ} \mathrm{C} . \mathrm{KNO}_{3}(15 \mathrm{~g}, 0.149 \mathrm{~mol})$ was added in portions over 10 minutes to the above solution and the reaction mixture is sequentially stirred for 10 hours at $110{ }^{\circ} \mathrm{C}$. The mixture is poured into $300 \mathrm{~mL}$ ice-water. The resulting precipitate is collected and washed with water thoroughly, dried and recrystallized from ether to give the pure product $(9 \mathrm{~g}$, yield $61 \%)$. M.p. $274-276^{\circ} \mathrm{C}$. MS: $141.3[\mathrm{M}+\mathrm{H}]^{+}, 163.1 \quad[\mathrm{M}+\mathrm{Na}]^{+} .{ }^{1} \mathrm{H}$ NMR $(400$ MHz,DMSO) $\delta 12.39$ (s, 1H), 8.89 (s, 1H), 7.87 (s, $1 \mathrm{H}), 6.57(\mathrm{~s}, 1 \mathrm{H})$.

\section{4-CHLORO-3-NITROPYRIDINE (9)}

3-Nitropyridin-4-ol (8) (5.5 g, $0.0393 \mathrm{~mol}$ ) was added to toluene $(16 \mathrm{~mL})$. The reaction flask was cooled to 0 degree and phosphoryl chloride $(25 \mathrm{~mL}, 0.27$ mol) was added dropwise. The mixture was blanketed with argon and heated to 110 degree for $2 \mathrm{~h}$. Upon complete consumption of the precursor, as indicated by TLC, the mixture was cooled to room temperature and $100 \mathrm{~mL}$ of $\mathrm{H}_{2} \mathrm{O}$ was added. The mixture was then cooled to 0 degree, and the resulting brown solid was filtered. Recrystallization from ethanol gave yellow crystals $(4.8 \mathrm{~g}, 0.21 \mathrm{~mol}$, $77 \%$ yield). M.p. $32^{\circ} \mathrm{C}$; MS: $159.2[\mathrm{M}+\mathrm{H}]+, 181.1$ $[\mathrm{M}+\mathrm{Na}]+$.

\section{$6 \quad N$-(4-BROMO-2-FLUOROPHENYL)-3- NITROPYRIDIN-4-AMINE (10)}

4-Bromo-2-fluoroaniline(2 g, $0.0105 \mathrm{~mol})(9)$ and 4bromo-2-fluoroaniline was dissolved in Acetic acid $(7 \mathrm{~mL})$ at room temperature. The reaction mixture was sequentially stirred for 10 hours at $25{ }^{\circ} \mathrm{C}$.After the completion of the reaction (monitored by TLC). Adjusting the $\mathrm{pH}$ to 8.5 , the precipitated solid was filtered. The filter cake was washed with water and then obtained a yellow product ( $3 \mathrm{~g}, 91.7 \%)$. MS: 312.1, 314.1 $[\mathrm{M}+\mathrm{H}]^{+}, 334.1,336.1[\mathrm{M}+\mathrm{Na}]^{+}$.

\section{N-4-(4-BROMO-2-FLUOROPHENYL) PYRIDINE-3,4-DIAMINE (11)}

$\mathrm{N}$-(4-bromo-2-fluorophenyl)-3-nitropyridin-4-amine (1 g, $0.0032 \mathrm{~mol})$ (10) was dissolved in ethanol (60 $\mathrm{mL})$ at room temperature. The reaction mixture was heated to $50^{\circ} \mathrm{C}$ and activated carbon $(1 \mathrm{~g}, 0.083$ $\mathrm{mol})$, ferric chloride $(0.5 \mathrm{~g}, 0.00308 \mathrm{~mol})$, hydrazine hydrate $(0.2 \mathrm{~g}, 0.004 \mathrm{~mol})$ was added and stir for $4 \mathrm{~h}$ at $80^{\circ} \mathrm{C}$. After the completion of the reaction (monitored by TLC). Cooled to room temperature, the precipitated solid was filtered. The filtrate was evaporated to dryness and washed with water and then obtained a scream product $(0.7 \mathrm{~g}, 83.4 \%)$. MS: $282,284[\mathrm{M}+\mathrm{H}]^{+}, 304.1,306.1[\mathrm{M}+\mathrm{Na}]^{+}$.

\section{1-(4-BROMO-2-FLUOROPHENYL)-1,3- DIHYDRO-2H-IMIDAZO[4,5-C]PYRIDIN-2- ONE(1)}

To a solution of N-4-(4-bromo-2fluorophenyl)pyridine-3,4-diamine (1 g, 0.0036 $\mathrm{moL})$ and triethylamine $(0.1 \mathrm{~g}, 1 \mathrm{mmol})$ in $30 \mathrm{~mL}$ of THF was added CDI ( $1 \mathrm{~g}, 0.006 \mathrm{~mol})$ at room temperature. The mixture was stirred at that temperature for $20 \mathrm{~h}$ and then the reaction mixture was poured into water $(100 \mathrm{~mL})$ and filtered. The filter cake was purified by washing with ether to afford $0.7 \mathrm{~g}$ of 1-(4-bromo-2-fluorophenyl)-1,3-dihydro$2 \mathrm{H}$-imidazo[4,5-c]pyridin-2-one (1) (63.1\% yield) MS: 308.1, $310.1[\mathrm{M}+\mathrm{H}]^{+} ; 332.1,330.2[\mathrm{M}+\mathrm{Na}]^{+}$. 


\section{CONCLUSIONS}

In conclusion,1-(4-bromo-2-fluorophenyl)-1,3dihydro-2H-imidazo[4,5-c]pyridin-2-one (1) was synthesized from pyridin-4-ol and $N$-(4-bromo-2fluorophenyl)-3-nitropyridin-4-aminethrough fjive steps including Nitration, chlorination, $\mathrm{N}$-alkylation, reduction and condensation. The synthetic method of the target compound (1) was optimized by changing conditions of the reaction so that can improve the yield. So the synthetic method can be used to synthesize 1-(4-bromo-2-fluorophenyl)-1,3-dihydro- $2 \mathrm{H}$ imidazo[4,5-c]pyridin-2-one (1) derivatives.

\section{ACKNOWLEDGMENTS}

We gratefully acknowledge the generous support provided by The National Natural Science Funds (No. 81460527), Science and Technology Project of Jiangxi Science \& Technology Normal University (2014XJYB002), Science and Technology Project Founded by the Education Department of Jiangxi Province (No. GJJ150796), Program of Key Laboratory of Drug Design and Optimization, Jiangxi Science \& Technology Normal University(300098010306), College Students' Science and Technology Innovation Project of Jiangxi Province and the Innovation Fund Designated for Graduate Students of Jiangxi Province (YC2015-X28).

\section{REFERENCES}

[1] Kumar Mahto M, Yellapu N K, Kilaru R B, et al. Molecular designing and in silico evaluation of darunavir derivatives as anticancer agents[J]. Bioinformation, 2014, 10(4): 221.

[2] Dayyani F, Gallick G E, Logothetis C J, et al. Novel therapies for metastatic castrate-resistant prostate cancer[J]. Journal of the National Cancer Institute, 2011, 103(22): 1665-1675.

[3] Bianchi M, Butti A, Rossi S, et al. Compounds with antiulcer and antisecretory activity. III: N-substituted imidazolones condensed with nitrogen-containing heteroaromatic rings[J]. European Journal of Medicinal Chemistry, 1983, 18(6): 501-506.

[4] Meanwell N A, Roth H R, Smith E C R, et al. 1, 3Dihydro-2H-imidazo [4, 5-b] quinolin-2-ones-inhibitors of blood platelet cAMP phosphodiesterase and induced aggregation[J]. Journal of medicinal chemistry, 1991, 34(9): 2906-2916.

[5] Capraro H G, Furet P, Garcia-Cheverria C, et al. 1HImidazo [4, 5-C] Quinoline Derivatives in the Treatment of Protein Kinase Dependent Diseases: U.S. Patent Application 10/579,876[P]. 2004-11-19.

[6] Chen Y L. Nitrogen compounds such as 2, 5, 6-trimethyl-7(1-propylbutyl)-4-(2, 4, 6-trimethylphenoxy)-7H-pyrrolo [2, 3-d] pyrimidine, used as Corticotropin-releasing factor (CRF) antagonists: U.S. Patent 6,992,188[P]. 2006-1-31.

[7] Seixas J D, Luengo-Arratta S A, Diaz R, et al. Establishment of a Structure-Activity Relationship of $1 \mathrm{H}$-Imidazo
[4, 5-c] quinoline-Based Kinase Inhibitor NVP-BEZ235 as a Lead for African Sleeping Sickness[J]. Journal of medicinal chemistry, 2014, 57(11): 4834-4848.

[8] Zhang P, Terefenko E A, Bray J, et al. 1-or 3-(3-Amino-2hydroxy-1-phenyl propyl)-1, 3-dihydro-2 H-benzimidazol-2ones: Potent, Selective, and Orally Efficacious Norepinephrine Reuptake Inhibitors $\uparrow+[J]$. Journal of medicinal chemistry, 2009, 52(18): 5703-5711. 